University of Rhode Island

DigitalCommons@URI

Cancer Prevention Research Center Faculty

Publications

Cancer Prevention Research Center

2011

Psychometric assessment of the Temptations to Try Alcohol

Scale

\author{
Magdalena Harrington \\ University of Rhode Island \\ Steven Babbin \\ University of Rhode Island \\ Colleen A. Redding \\ University of Rhode Island, credding@uri.edu \\ Caitlin Burditt \\ University of Rhode Island \\ Andrea L. Paiva

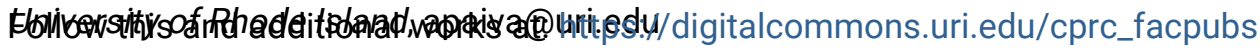 \\ This is a pre-publication author manuscript of the final, published article. \\ Greative Commons licicensen \\ (c) (1) $(9)$
}

This work is licensed under a Creative Commons Attribution-Noncommercial-No Derivative Works 4.0 License.

\author{
Citation/Publisher Attribution \\ Harrington, M., Babbin, S., Redding, C., Burditt, C., Paiva, A., Meier, K., Oatley, K.,...Velicer, W. F. (2011). \\ Psychometric assessment of the Temptations to Try Alcohol Scale. Addictive Behaviors, 36(4), 431-433. \\ doi: 10.1016/j.addbeh.2010.12.019 \\ Available at: https://doi.org/10.1016/j.addbeh.2010.12.019
}

This Article is brought to you for free and open access by the Cancer Prevention Research Center at DigitalCommons@URI. It has been accepted for inclusion in Cancer Prevention Research Center Faculty Publications by an authorized administrator of DigitalCommons@URI. For more information, please contact digitalcommons-group@uri.edu. 


\section{Authors}

Magdalena Harrington, Steven Babbin, Colleen A. Redding, Caitlin Burditt, Andrea L. Paiva, Kathryn Meier, Karin Oatley, Heather McGee, and Wayne F. Velicer 


\title{
Psychometric Assessment of the Temptations to Try Alcohol Scale
}

\author{
Magdalena Harrington, MA, Steven Babbin, BS, Colleen Redding, PhD, Caitlin Burditt, MA, \\ Andrea Paiva, PhD, Kathryn Meier, MPH, Karin Oatley, MA, Heather McGee, BS, and Wayne \\ Velicer, PhD \\ Cancer Prevention Research Center, University of Rhode Island
}

\begin{abstract}
Effective interventions require an understanding of the behaviors and cognitions that facilitate positive change as well as the development of psychometrically sound measures. This paper reports on the psychometric properties of the Temptations to Try Alcohol Scale (TTAS), including factorial invariance across different subgroups. Data were collected from 3565 6th grade RI middle school students. Structural equation modeling was used to determine the appropriate factorial invariance model for the 9-item TTAS. The measure consists of three correlated subscales: Social Pressure, Social Anxiety, and Opportunity. Three levels of invariance, ranging from the least to the most restrictive, were examined: Configural Invariance, which constrains only the factor structure and zero loadings; Pattern Identity Invariance, which requires factor loadings to be equal across the groups; and Strong Factorial Invariance, which requires factor loadings and error variances to be constrained. Separate analyses evaluated the invariance across two levels of gender (males vs. females), race (white vs. black) ethnicity (Hispanic vs. NonHispanic) and school size (small, meaning $<2006^{\text {th }}$ graders, or large). The highest level of invariance, strong factorial invariance, provided a good fit to the model for gender (CFI: .95), race (CFI: .94), ethnicity (CFI: .94), and school size (CFI: .97). Coefficient Alpha was .90 for Social Pressure, .81 for Social Anxiety, and .82 for Opportunity. These results provide strong empirical support for the psychometric structure and construct validity of the TTAS in middle school students.
\end{abstract}

\section{Keywords}

Factorial Invariance; Self-efficacy; Situational Temptations; Transtheoretical Model; Alcohol Prevention

Rates of alcohol use increase throughout middle school years, despite serious negative consequences. To effectively intervene on the problem of alcohol use, measures must be developed that assess behaviors and cognitions relevant to the problem. The transtheoretical

\footnotetext{
(C) 2010 Elsevier Ltd. All rights reserved.

Contact person: Wayne Velicer, Cancer Prevention Research Center, 2 Chaffee Rd., University of Rhode Island, Kingston, Rhode Island 02881 United States.

Requests for reprints should be sent to Wayne F. Velicer, Cancer Prevention Research Center, 2 Chafee Road, University of Rhode Island, Kingston, RI, 02881-0808. velicer@uri.edu. Website: www.uri.edu/research/cprc.

Publisher's Disclaimer: This is a PDF file of an unedited manuscript that has been accepted for publication. As a service to our customers we are providing this early version of the manuscript. The manuscript will undergo copyediting, typesetting, and review of the resulting proof before it is published in its final citable form. Please note that during the production process errors may be discovered which could affect the content, and all legal disclaimers that apply to the journal pertain.

An early version of this paper was presented at the Society for Prevention Research Meeting, Denver, CO, June, 2010.
} 
model of behavior change (TTM; Prochaska \& Velicer, 1997; Velicer et al., 2000) is an integrative framework made up of multiple dimensions. The TTM has been validated in many studies and has been used to develop many effective, population-based interventions (Velicer et al., 2000). The core constructs of TTM include stages of change, processes of change, decisional balance, and self-efficacy (or situational temptations). The Situational Temptations Scale assesses an individual's desire to perform a behavior in difficult situations (Velicer, DiClemente, Rossi, \& Prochaska, 1990) and is based on the self-efficacy construct of Bandura $(1977 ; 1982)$ and the relapse prevention literature. This paper describes a variation of the measure, designed for the prevention of alcohol acquisition with middle school students. Based on preliminary results (Burditt, Harrington, Redding, Velicer, Paiva, Meier, Oatley, \& Prochaska, 2009), the Temptations to Try Alcohol Scale (TTAS) is a correlated three-factor model with nine items; three items each for Social Pressure, Social Anxiety, and Opportunity. The measure is currently being used in a computerized multimedia alcohol prevention program which delivers interactive interventions tailored to each student's particular risk profile. To be a useful part of the intervention, the TTAS must be reliable and valid; the goal of this paper is to assess the psychometric properties of the scale, including factorial invariance.

Factorial invariance is critical to establishing psychometric properties of any measure. It determines whether the set of items assesses the same theoretical constructs across different subgroups (Meredith \& Teresi, 2006). This paper reports on the factorial invariance across subgroups defined by gender, ethnicity, race, and school size. This scale has been previously validated among high school students and more recently, in a large sample of middle school students (Burditt et al., 2009). In this paper different levels of factorial invariance are examined in a sequential order with increasingly constrained models to assess the equivalence of the Temptations to Try Alcohol Scale across different subsamples.

The first level of invariance examined was Configural Invariance, also called weak factorial invariance, which is an unconstrained model for the non-zero loadings and assumes the same number of factors and same items associated with each factor are found across subpopulations (Meredith, 1993; Meredith \& Teresi, 2006). Configural invariance is a prerequisite for testing any more constrained measurement invariance models. The second level of invariance, Pattern Identity Invariance, requires that factor loadings are invariant across groups. The highest level, Strong Factorial Invariance, requires invariant factors and error variances. Meaningful group comparisons can be assumed when strong factorial invariance is observed (Meredith, 1993; Meredith \& Teresi, 2006). Coefficient Alphas for each subgroup was also calculated to assess scale reliability.

\section{Method}

\section{Participants}

Data used in this paper were collected from 3565 6th grade Rhode Island middle school students from 20 schools. The data comes from an ongoing study that delivers computerized a multi-media alcohol and tobacco prevention program based on TTM framework. The sample was $82 \%$ white and $48 \%$ female.

\section{Procedure}

Structural equation modeling was used to determine the most appropriate factorial invariant model for the 9-item Temptations to Try Alcohol Scale. Three levels of invariance, ranging from the least to the most restrictive were examined. This paper evaluated the invariance across two levels of gender (male, $\mathrm{n}=1827$ and female, $\mathrm{n}=1709$ ), race (White, $\mathrm{n}=2346$ and Black = 98) ethnicity (Hispanic, $\mathrm{n}=3005$ and Non-Hispanic, $\mathrm{n}=479$ ) and school size 
( $<2006^{\text {th }}$ graders, $n=1242$ and $>2006^{\text {th }}$ graders, $\left.n=2309\right)$. Each subgroup consisted of at least 98 participants, which is an adequate sample size for the model to converge (Velicer \& Fava, 1998).

\section{Temptations to Try Alcohol Scale}

The Temptations to Try Alcohol Scale consists of three correlated subscales: Social Pressure, Social Anxiety, and Opportunity (see Figure 1). The sequential method of scale development (Jackson, 1971) was used to create the measure. It has been previously evaluated among high school students and more recently, in a sample of middle school students (Burditt et al., 2009).

\section{Factorial invariance}

All levels of invariance: configural invariance, pattern identity invariance, and strong factorial invariance were assessed using the following indices: comparative fit index (CFI), normed fit index (NFI), nonnormed fit index (NNFI), and root mean square error of approximation (RMSEA). Values of at least .90 are considered acceptable and values greater than .95 are preferable (Bentler, 1990) for CFI, NFI and NNFI. For RMSEA, values less than .08 are acceptable and below.05 are preferable (Hu \& Bentler, 1999). In addition, a CFI difference between a model and the level of invariance below it was calculated to determine whether a null hypothesis of invariance should be rejected. A value of -0.01 or less indicates measurement invariance (Cheung \& Rensvold, 2002).

\section{Results}

\section{Factorial invariance of Temptations to Try Alcohol Scale}

Structural equation modeling (SEM) performed with EQS software (Bentler, 2004) was used to examine hierarchical factorial invariance (See Table 1 for detailed results).

Gender

Strong factorial invariance provided a good fit for the model, with $\mathrm{n}=1837$ for males and $\mathrm{n}$ $=1714$ for females $(\mathrm{CFI}=.951 ; \mathrm{NFI}=.948 ; \mathrm{NNFI}=.939 ; \mathrm{RMSEA}=.109)$.

\section{Ethnicity}

Strong factorial invariance provided a good fit for the model, with $\mathrm{n}=3004$ for NonHispanic and $n=478$ for Hispanic $(\mathrm{CFI}=.944$; NFI $=.942 \mathrm{NNFI}=.932$ RMSEA $=.115)$.

\section{Race}

Strong factorial invariance provided a good fit for the model, with $\mathrm{n}=2351$ for White and $\mathrm{n}$ $=97$ for Black $(\mathrm{CFI}=.936 ; \mathrm{NFI}=.933, \mathrm{NNFI}=.922 \mathrm{RMSEA}=.124)$.

\section{School size}

Strong factorial invariance provided a very good fit for the model, with $\mathrm{N}=1242$ for small school size $\left(<2006^{\text {th }}\right.$ graders), and $\mathrm{N}=2309$ for large school size $\left(>2006^{\text {th }}\right.$ graders $)$ (CFI $=.967 ; \mathrm{NFI}=.965 \mathrm{NNFI}=.960 \mathrm{RMSEA}=.089)$.

\section{Scale reliabilities}

Strong factorial invariance was adequate for all of the subsamples, so Cronbach's Coefficient Alpha was calculated only for the total sample (see Figure 1 for the structure). Coefficient Alpha $=.90$ for Social Pressure, .81 for Social Anxiety, and .82 for Opportunity. 


\section{Discussion}

Examination of fit indices of each of four models of factorial invariance indicate that strong factorial invariance of the three-factor model of Temptations to Try Alcohol Scale has a good fit across all subgroups, with most fit indices of NFI, NNFI and CFI around .95. This provides empirical support for the internal validity of the scale.

Although NFI, NNFI and CFI fit indices for strong factorial invariance are above .90 for all subgroups, which indicates acceptable fit of the model, the analysis of $\Delta \mathrm{CFI}$ is less consistent across subgroups. For gender, ethnicity, and race, $\Delta \mathrm{CFI}$ is slightly higher than proposed cut off value $(-0.01)$, suggesting that there could be some differences in error measurement within these two subgroups, and further research is needed to explore this inconsistency. However, the highest level of invariance can be difficult to obtain in most measures and the results are not indicators of unreliable measure. Also, unequal and small sample sizes for race and ethnicity subgroups could cause the relatively high RMSEA values. Sample sizes of less than 250 impact the reliability of RMSEA estimate (Hu \& Bentler, 1999).

These results demonstrate that Temptations to Try Alcohol Scale can be used in multiple subgroups and legitimate comparisons can be made among manifest variables across different populations. The Temptations to Try Alcohol Scale is invariant across factor loadings and error variances across gender, ethnicity, race and school size, and it is a psychometrically sound measure.

\section{Acknowledgments}

This paper was partially supported by Grant CA11919 from NCI and Grant DA020112 from NIDA.

\section{References}

Bandura A. Self-efficacy: Toward a unifying theory of behavior change. Psychological Review 1977;84:191-215. [PubMed: 847061]

Bandura A. Self-efficacy mechanisms in human agency. American Psychologist 1982;37:122-147.

Bentler PM. Comparative fit indices in structural models. Psychological Bulletin 1990;107:238-246. [PubMed: 2320703]

Burditt, C.; Harrington, H.; Redding, C.; Velicer, W.; Paiva, A.; Meier, K.; Oatley, K.; Prochaska, J. Decisional balance and temptations for alcohol use in middle school adolescents. Poster session presented at the annual meeting of the Society for Prevention Research; 2009, May; Washington, D.C..

Cheung GW, Rensvold RB. Evaluating goodness-of-fit indexes for testing measurement invariance. Structural Equation Modeling 2002;9:233-255.

$\mathrm{Hu}$ L, Bentler PM. Cutoff criteria for fit indexes in covariance structure analysis: Conventional criteria versus new alternatives. Structural Equation Modeling 1999;6:1-55.

Jackson DN. The dynamics of structured personality tests: 1971. Psychological Review 1971;78:229_ 248.

Meredith W. Measurement invariance, factor analysis, and factorial invariance. Psychometrika 1993;58:525-543.

Meredith W, Teresi JA. An essay on measurement and factorial invariance. Medical Care 2006; vol. 44; suppl 11(nr 11):S69-S77. [PubMed: 17060838]

Prochaska JO, Velicer WF. The Transtheoretical Model of Behavior Change. American Journal of Health Promotion 1997;12:38-48. [PubMed: 10170434]

Velicer WF, DiClemente C, Rossi JS, Prochaska JO. Relapse situations and self-efficacy: An integrative model. Addictive Behaviors 1990;15:271-283. [PubMed: 2378287] 
Velicer WF, Fava JL. The effects of variable and subject sampling on factor pattern recovery. Psychological Methods 1998;3:231-251.

Velicer WF, Prochaska JO, Fava JL, Rossi JS, Redding CA, Laforge RG, Robbins ML. Using the Transtheoretical Model for Population-based Approaches to Health Promotion and Disease Prevention. Homeostasis in Health and Disease 2000;40:174-195. 


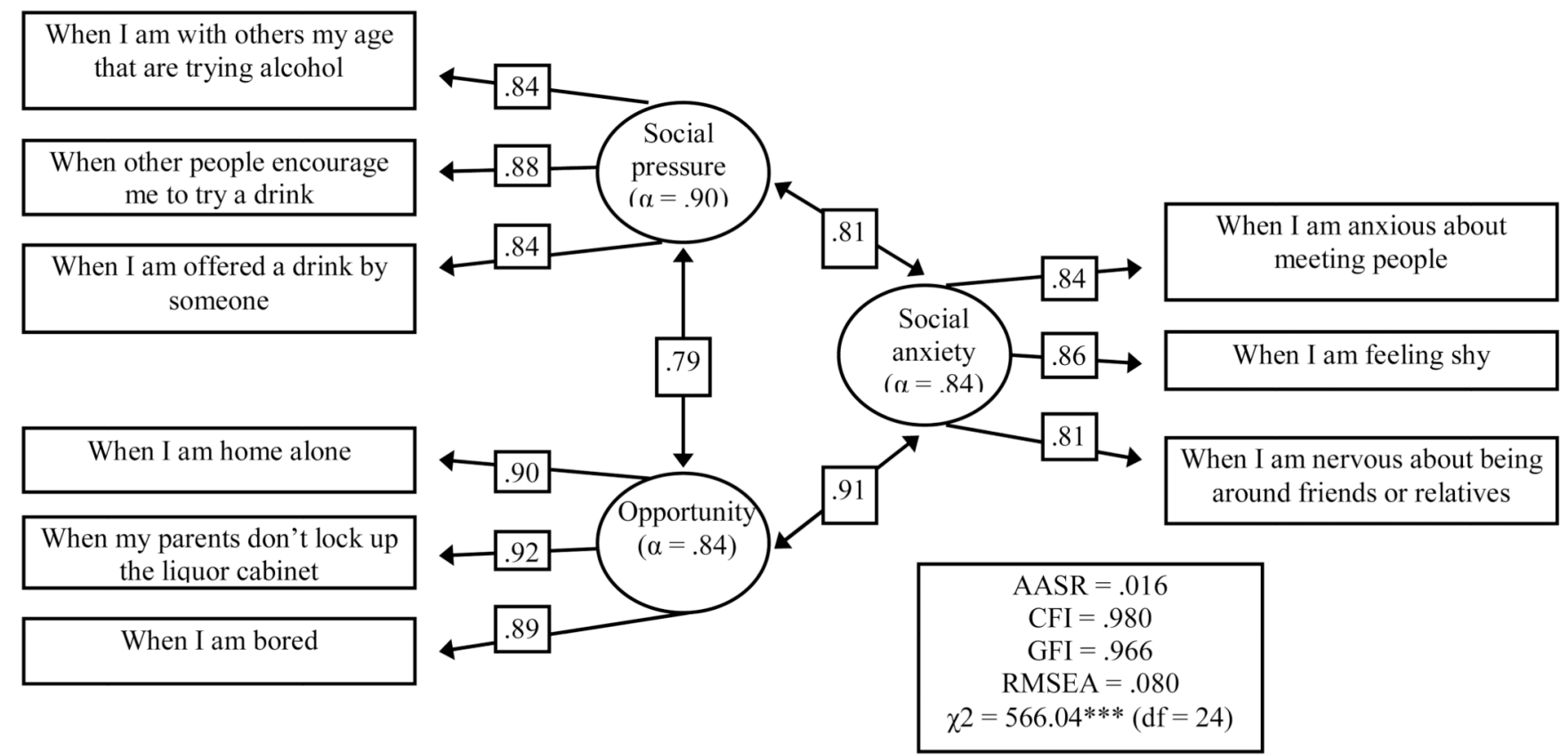

Figure 1.

CFA model of the Temptations to Try Alcohol Scale 


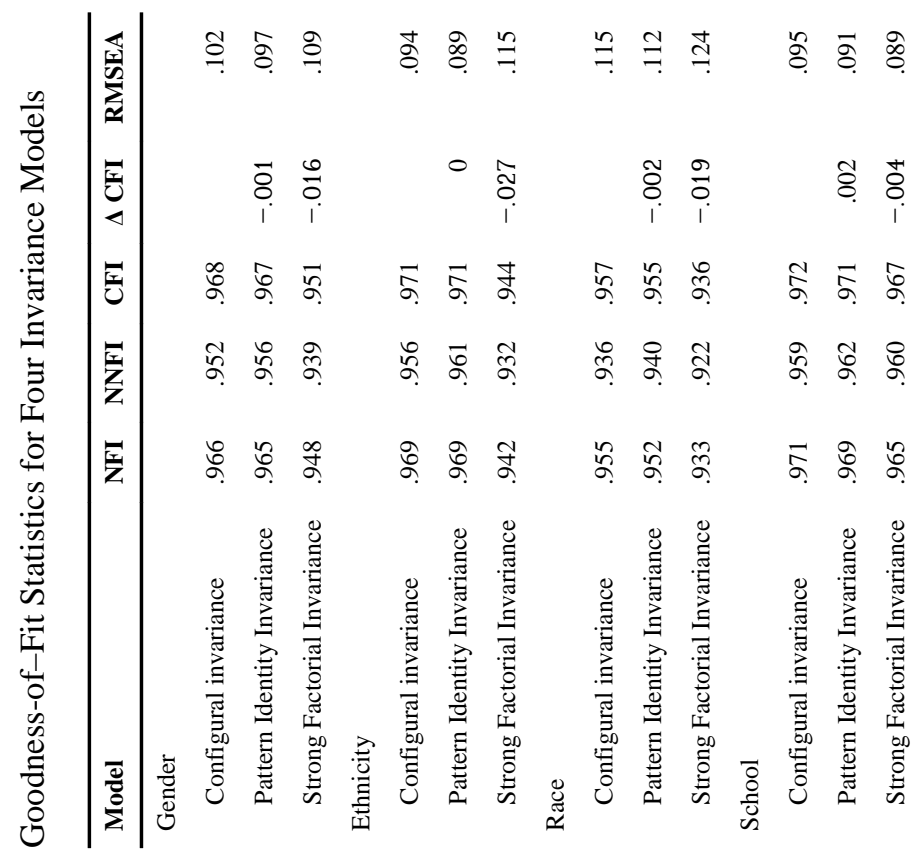

